\title{
Apolipoprotein Synthesis in Newborn Piglet Intestinal Explants
}

\author{
DENNIS D. BLACK AND HERODOTOS ELLINAS \\ Department of Pediatrics, Wyler Children's Hospital, Pritzker School of Medicine, University of Chicago, \\ Chicago, Illinois 60637
}

\begin{abstract}
To determine the effects of hormones and epidermal growth factor (EGF) on the small intestinal synthesis of apolipoproteins B-48, A-I, and A-IV in the neonatal mammal, apolipoprotein synthesis by proximal jejunal explants from 2-d-old female piglets was studied in tissue culture. Initial comparison studies with various media showed optimal total protein and apo A-I synthesis with Williams' medium $E$ without fetal bovine serum. Sets of explants were prepared containing EGF and various hormones in the medium. After ${ }^{35} \mathrm{~S}$-methionine radiolabeling, explants were homogenized, and specific apolipoprotein synthesis was quantitated by immunoprecipitation as the percentage of total protein synthesis. Apo B-48 synthesis was not affected by any additives except the combination of EGF and hydrocortisone, which slightly decreased synthesis. Apo A-I synthesis was significantly increased by EGF. This EGF-induced increase in apo A-I synthesis was blunted by concomitant treatment with hydrocortisone. In contrast, the combination of insulin and hydrocortisone induced a significant increase in apo A-I synthesis. Although EGF and insulin modestly increased apo A-IV synthesis, the combination of insulin and hydrocortisone treatment up-regulated apo A-IV synthesis by 2.6-fold. Thyroid hormone lacked effect on synthesis of any of the apolipoproteins. EGF, glucocorticoids, and insulin may play regulatory roles in the developmental expression of apolipoprotein synthesis in the neonatal small intestine. (Pediatr Res 32: 553-558, 1992)
\end{abstract}

\section{Abbreviations}

EGF, epidermal growth factor

FBS, fetal bovine serum

Apolipoproteins are surface components of lipoprotein particles and serve essential functions in the secretion, metabolism, and receptor-mediated uptake of these particles. Apo B is present in triglyceride-rich lipoproteins, and there are two distinct forms of apo B in the human, rat, and swine (1-3). Apo B-100 is the larger form and is a component of plasma VLDL and LDL and contains the LDL receptor binding domain (4). Apo B-48 is the smaller species found in intestinal chylomicrons and does not contain the LDL receptor binding domain (5). In the postnatal human and swine, apo B-100 and apo B-48 are predominately of hepatic and intestinal origin, respectively $(1,6)$. In both liver and intestine, apo $B$ is thought to be essential for the packaging and secretion of triglyceride-rich lipoproteins (3).

Received January 10, 1992; accepted June 18, 1992.

Correspondence: Dennis D. Black, M.D., Wyler Children's Hospital, 5825 S. Maryland Ave., Box 107, Chicago, IL 60637.

Supported by NIH Grant R29 HD22551 (D.D.B.) and a Kraft Foundation Medical Student Fellowship (H.E.).
Apo A-I is the major apolipoprotein of plasma HDL and is produced by both liver and intestine in the human, rat, and swine $(1,7-10)$. Its major metabolic role is that of a cofactor for lecithin:cholesterol acyltransferase, the enzyme responsible for the production of most plasma cholesteryl esters (11). Apo A-IV is a component of nascent intestinal lipoproteins, including chylomicrons and HDL (12-15), and becomes dissociated from chylomicrons soon after secretion $(16,17)$. The major metabolic function of apo A-IV is presently unknown. Recent in vitro studies have suggested roles in the activation of lecithin:cholesterol acyltransferase $(18,19)$ and in reverse cholesterol transport by promoting cellular cholesterol efflux (20) and serving as a ligand for HDL binding to hepatocytes (21).

The small intestine plays a key role in neonatal lipid metabolism because of the importance of dietary lipid as a nutrient source during this period. Potential factors responsible for the developmental regulation of small intestinal function include diet, the microenvironment of the enterocyte (hormones, growth factors, and the extracellular matrix), and preprogrammed genetic cues. Because apolipoproteins are crucial to the biogenesis and peripheral metabolism of lipoproteins, regulation of their expression in the developing gut is of obvious importance. Studies of the developmental regulation of intestinal lipoprotein metabolism have been largely performed in the rat (22-26), an altricial species as compared with the precocial human. We have developed a swine model for the study of intestinal apolipoprotein gene expression in the developing mammal (1, 27-29). The swine is a precocial mammal and has significant homology with the human with regard to lipoprotein metabolism $(1,7,27,28)$ and intestinal development in general (30). We have so far shown distinct regulatory patterns for intestinal expression of apo B, apo A-I, and apo A-IV induced by dietary and biliary lipid in the neonatal and older suckling piglet using an in vivo model (1, 27-29). To study the potential regulatory roles of hormones and growth factors, a system for the short-term culture of newborn piglet intestinal explants in serum-free medium was developed. This system offers the advantages of control over the microenvironment of the enterocytes while maintaining the native extracellular matrix. In the present report, the effects of hydrocortisone, insulin, thyroid hormone, and EGF on apolipoprotein synthesis in newborn piglet jejunal explants were studied.

\section{MATERIALS AND METHODS}

Animals. Two-d-old female domestic swine were obtained from Research Industries Corporation (Monee, IL).

Jejunal explant preparation. From the time of arrival to the time of surgery the next day, the 2-d-old animals were kept in heated isolettes. Animals were fed artificial sow's milk (SPFLAC, Pet-Ag, Inc., Hampshire, IL) by gavage during this period. Anesthesia was induced by intramuscular ketamine at a dose of $0.15 \mathrm{mmol} / \mathrm{kg}(40 \mathrm{mg} / \mathrm{kg})$ and maintained by face mask delivering $1 \mathrm{~L} / \mathrm{min} \mathrm{O}_{2}$ and $0.5-0.8 \%$ halothane. A longitudinal midline abdominal incision was made, and the peritoneal cavity was 
opened. Starting $10 \mathrm{~cm}$ distal to the ligament of Treitz, a $20-\mathrm{cm}$ segment of proximal jejunum was isolated with ligatures and removed. The lumen of the segment was then rinsed with PBS followed by Earle's balanced salt solution. The segment was placed in Earle's balanced salt solution for transport to the laboratory. The segment was then opened longitudinally, and $2 \times 2 \mathrm{~mm}$ explants were prepared with the serosa and muscularis mucosae intact. Explants were then placed on nylon grids in Falcon tissue culture dishes (Becton Dickinson and Co., Lincoln Park, NJ) (six explants per dish) (31). Explants for the first part of the study, determining optimal culture conditions, were derived from three piglets. All explants for the portion of the study examining the effects of EGF and hormones were derived from two animals contributing explants to all experimental groups.

Explant culture. Initial studies were designed to identify the optimum culture medium for the explants to support apolipoprotein synthesis. A variety of culture media were tested including minimum essential medium of Eagle, Dulbecco's modified Eagle medium, cell suspension modified Eagle medium, Williams' medium E, Leibovitz's medium L-15, and RPMI 1640 medium with and without FBS at a concentration of $10 \%$. In these initial studies, explants were cultured for $18 \mathrm{~h}$ in a humidified incubator at $37^{\circ} \mathrm{C}$ in $5 \% \mathrm{CO}_{2}$. Then $15 \mu \mathrm{Ci}{ }^{35} \mathrm{~S}$-methionine (Amersham, Arlington Heights, IL) in fresh medium were added to each culture dish for a $6-\mathrm{h}$ incubation for a total culture time of $24 \mathrm{~h}$. All media contained $20 \mathrm{mmol} / \mathrm{L} \mathrm{4-(2-hydroxyethyl)-1-}$ piperazine ethanesulfonic acid, $2 \mathrm{mmol} / \mathrm{L}$, glutamine, and antibiotics.

After optimization of basal culture conditions, explant cultures were carried out with the addition of the following hormones and growth factors to the medium: EGF at $82.6 \mathrm{nmol} / \mathrm{L}$ (500 $\mathrm{ng} / \mathrm{mL})$, insulin at $43.6 \mathrm{pmol} / \mathrm{L}(6 \mathrm{mU} / \mathrm{mL})$, hydrocortisone at $138 \mathrm{nmol} / \mathrm{L}(50 \mathrm{ng} / \mathrm{mL})$, and thyroxine at $64.4 \mathrm{pmol} / \mathrm{L}(0.05$ $\mathrm{ng} / \mathrm{mL}$ ). Besides studying the effects of these additives singly, the following combinations were studied at the same individual concentrations: insulin plus hydrocortisone and EGF plus hydrocortisone. These additives were present in the culture media during the entire culture period with radiolabeling carried out during the final $6 \mathrm{~h}$ of culture.

Apolipoprotein immunoprecipitation. After incubation, explants were rinsed in cold PBS and homogenized in PBS containing $20 \mathrm{mmol} / \mathrm{L}$ unlabeled methionine, $1 \%$ Triton X100, 1 $\mathrm{mmol} / \mathrm{L}$ phenylmethylsulfonyl fluoride, $1 \mathrm{mmol} / \mathrm{L}$ benzamidine, and $1 \mathrm{mmol} / \mathrm{L}$ leupeptin, $\mathrm{pH}$ 7.4. Aliquots of the homogenate were taken for measurement of total protein concentration and trichloroacetic acid-precipitable radioactivity. The remainder was pelleted at $105000 \times g$ for $60 \mathrm{~min}$ in a 50.3 titanium rotor (Beckman Instruments, Palo Alto, CA), followed by collection of the supernatant. Although most intracellular apolipoprotein is membrane-associated, this technique has been shown previously to result in extraction and solubilization of $84-94 \%$ of total recoverable apolipoprotein mass (32). All procedures were performed at $0-5^{\circ} \mathrm{C}$, and the supernatant samples were stored at $-80^{\circ} \mathrm{C}$ until analysis. Intestinal supernatant fractions were subjected to specific immunoprecipitation of apo B, apo A$\mathrm{I}$, and apo A-IV under conditions of antibody excess as described $(27,28)$. Aliquots of supernatants were mixed with washed $\mathrm{IgG}-$ Sorb (The Enzyme Center, Malden, MA) and subsequently reacted with excess anti-apolipoprotein antiserum for $18 \mathrm{~h}$ at $4^{\circ} \mathrm{C}$. After a second addition of IgG-Sorb and extensive washing, the liberated immunocomplex was applied to either 5.6\% (apo A-I and apo A-IV) or 4\% (apo B) SDS polyacrylamide tube gels $(27,28)$. After electrophoresis, gels were sliced into $1-\mathrm{mm}$ slices and incubated in 3\% Protosol/97\% Econofluor (New England Nuclear, Boston, MA) at $37^{\circ} \mathrm{C}$ overnight before liquid scintillation counting in a Packard Model 2000 liquid scintillation counter (Packard Instruments, Downers Grove, IL). Apolipoprotein species were identified by comparison to stained coelectrophoresed apolipoproteins. Apolipoprotein synthesis rates were expressed as the percentage of specific immunoprecipitated apo- protein counts compared with total protein trichloroacetic acidprecipitable counts. Apolipoprotein synthesis was thereby expressed as a percentage of total protein synthesis. All samples were subjected to reimmunoprecipitation to ensure the completeness of the first antigen-antibody reaction. Total protein content of the explant homogenates was measured by a modified Lowry technique (33).

Statistical analysis. Data in experimental groups (control and treatment with hormones and EGF) were analyzed by one-way analysis of variance followed by the Student-Newman-Keuls test to compare specific groups. The null hypothesis was rejected at $p<0.05$.

\section{RESULTS}

Total protein and apo A-I synthesis with various culture media with and without FBS. Figures 1 and 2 show total protein sp act and apo A-I synthesis, respectively, with explants cultured in various media with and without FBS. Each bar represents the means of data from two culture dishes containing six explants

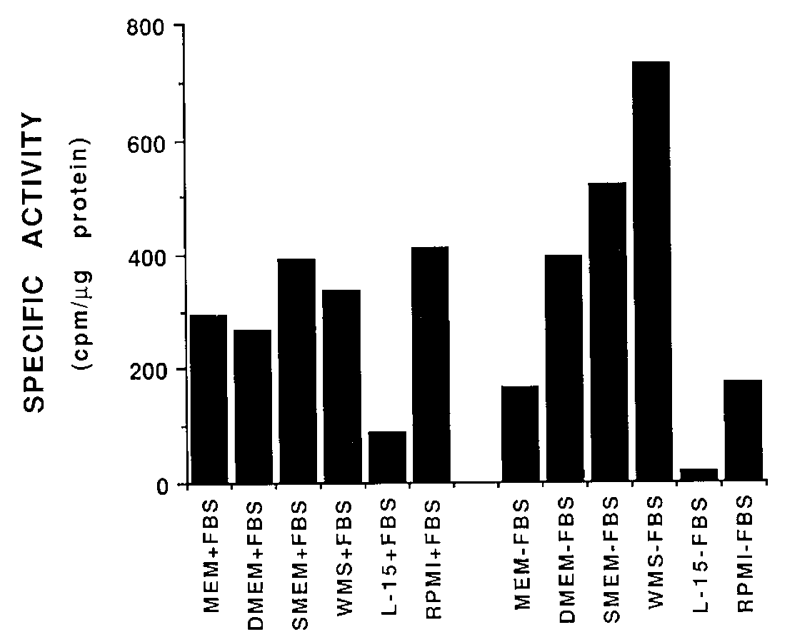

Fig. 1. Homogenate sp act from jejunal explants cultured in various media. Media tested include minimum essential medium of Eagle $(M E M)$, Dulbecco's modified Eagle medium ( $D M E M)$, cell suspension modified eagle medium ( $S M E M)$, Williams' medium E (WMS), Leibovitz's medium L-15 (L-15), and RPMI 1640 medium (RPMI) with and without FBS $( \pm$ FBS, $10 \%)$. Bars represent the mean of data from two culture dishes of explants (6 explants/dish).

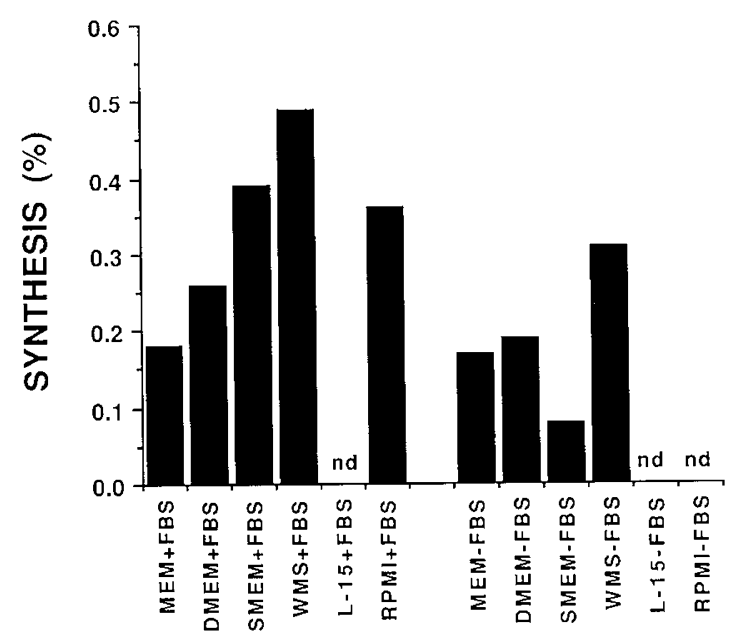

Fig. 2. Apo A-I synthesis in jejunal explants cultured in various media with and without FBS. Abbreviations for the various culture media are the same as in Figure 1. Bars represent the mean of data from two culture dishes of explants (6 explants/dish). nd, none detectable. 
per dish. Williams' medium E without FBS clearly supported the highest explant homogenate sp act. Although apo A-I synthesis (Fig. 2) in this medium was somewhat higher with the addition of FBS than without, this medium yielded the highest apo A-I synthesis when compared with the other media with or without FBS supplementation. Because we preferred to use serum-free medium in our studies with hormone and growth factor supplementation, Williams' medium $\mathrm{E}$ was used in all subsequent experiments. Additionally, in subsequent studies we shortened the total culture time to $12 \mathrm{~h}$ with radiolabeling during the final $6 \mathrm{~h}$, as this resulted in higher basal apo A-I synthesis compared with the longer culture time (1.46 versus $0.31 \%$ of total protein synthesis).

Effect of hormones and growth factors on explant total protein and apolipoprotein synthesis. Data from these studies are depicted in Figures 3-6. Each bar represents data (mean \pm SEM) from five culture dishes containing six explants per dish. Figure 3 shows total protein sp act of radiolabeled homogenates from the various experimental groups. A modest, yet significant, increase in radiolabel incorporation is seen with EGF treatment. Yet, a 9-fold increase is induced by treatment with the combination of insulin and hydrocortisone.

Apo A-I synthesis is shown in Figure 4. Paralleling the changes

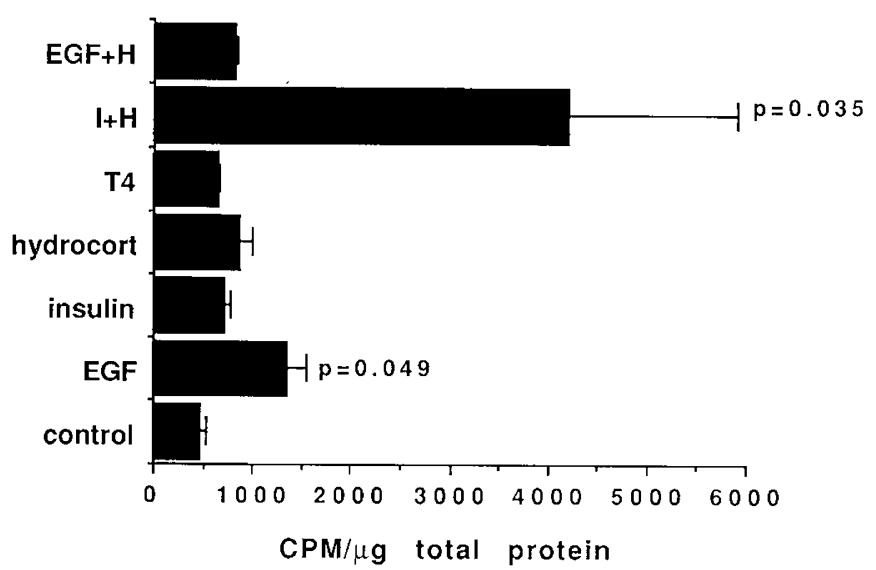

Fig. 3. Homogenate sp act from newborn piglet jejunal explants cultured with EGF, insulin, hydrocortisone ( hydrocort), thyroid hormone $(T 4)$, insulin plus hydrocortisone $(I+H)$, and EGF plus hydrocortisone $(E G F+H)$. Control explant medium contained no additives. Bars represent mean \pm SEM of data from five culture dishes of explants $(6$ explants/dish). Statistically significant differences from the control values are indicated by the designated $p$ values.

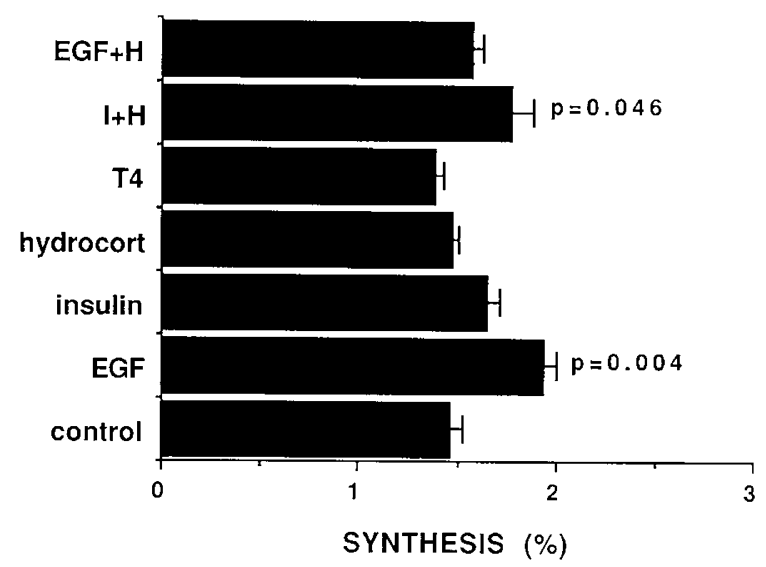

Fig. 4. Apo A-I synthesis as a percentage of total protein synthesis in jejunal explants cultured with hormones and EGF (abbreviations are the same as in Fig. 3). Bars represent mean \pm SEM of data from five culture dishes of explants (6 explants/dish). Statistically significant differences from the control values are indicated by the designated $p$ values.

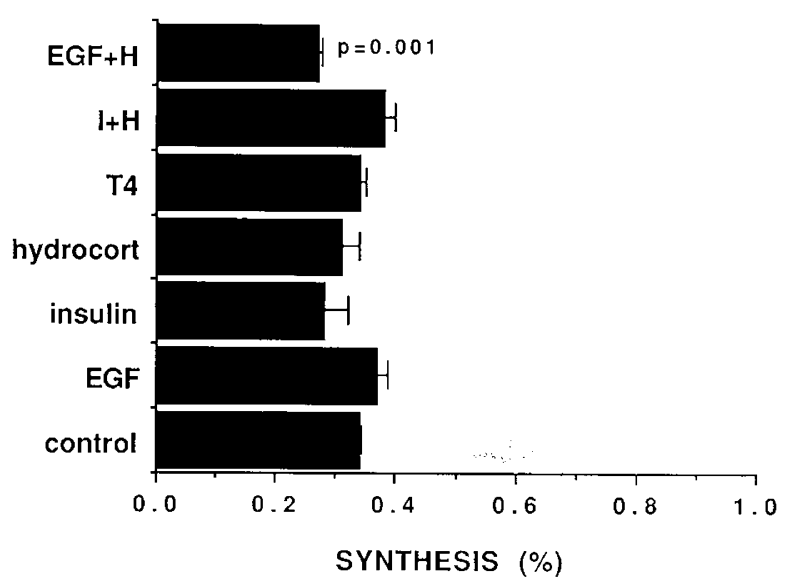

Fig. 5. Apo B synthesis as a percentage of total protein synthesis in jejunal explants cultured with hormones and EGF (abbreviations are the same as in Fig. 3). Bars represent mean \pm SEM of data from five culture dishes of explants ( 6 explants/dish). Statistically significant differences from the control values are indicated by the designated $p$ values.

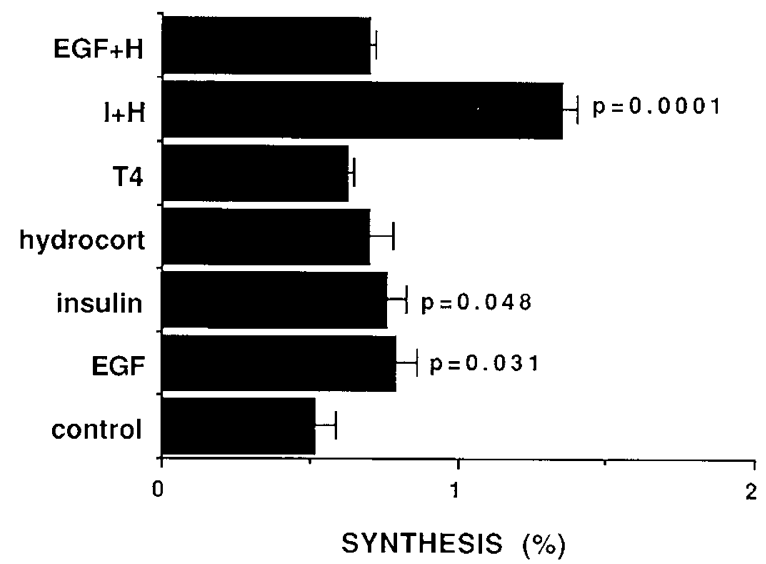

Fig. 6. Apo A-IV synthesis as a percentage of total protein synthesis in jejunal explants cultured with hormones and EGF (abbreviations are the same as in Fig. 3). Bars represent mean \pm SEM of data from five culture dishes of explants (6 explants/dish). Statistically significant differences from the control values are indicated by the designated $p$ values.

in total protein radiolabeling are modest, but significant, increases in apo A-I synthesis with EGF and the combination of insulin and hydrocortisone. The increase induced by EGF is not present with concomitant treatment with hydrocortisone. Figure 5 shows apo B synthesis. None of the additives had a significant effect except a modest, though statistically significant, decrease in synthesis with the combination of EGF and hydrocortisone. Only apo B-48 synthesis, not apo B-100, was identified in all the samples. Apo A-IV synthesis is shown in Figure 6. Although EGF and insulin individually increase apo A-IV synthesis to a modest degree, the combination of insulin and hydrocortisone treatment up-regulates apo A-IV synthesis by 2.6 -fold. Thyroid hormone appears to have no effect on explant synthesis of any of the apolipoproteins studied.

\section{DISCUSSION}

The first phase of the present studies involved the testing of several different standard culture media for their suitability in supporting active total protein and apolipoprotein synthesis by jejunal explants from the newborn piglet. Media were tested both in the presence and absence of FBS. Obviously, for our studies of the effects of hormones and growth factors, serum-free culture conditions were preferred. Based on previously reported studies of the serum-free culture of fetal human intestinal explants (34, 
35), we expected Leibovitz's medium L-15 to be optimum. In fact, this medium exhibited the worst total protein synthesis of all the media, and no apo A-I synthesis could be detected. Interestingly, a medium developed for the culture of rat hepatocytes, Williams' medium E, proved to be the best medium, particularly under serum-free conditions. Compositional analysis of the media revealed two major differences between these media. First, the L-15 medium contains galactose as the only carbohydrate source, whereas Williams' medium E and the other media contain only glucose, suggesting that the former may not be a suitable carbohydrate substrate for these cells. Second, Williams' medium $\mathrm{E}$ was the only medium tested to contain lipid (linoleate as the methyl ester at $10^{-7} \mathrm{~mol} / \mathrm{L}$ ), which may be required for in vitro apolipoprotein expression. Regardless of the reason, Williams' medium E was clearly the most suitable medium for the study of apolipoprotein synthesis in newborn piglet intestinal explants.

Most work to date involving the developmental biology of the mammalian small intestine has examined the role of hormones and growth factors in the maturation of the rodent small intestine $(22,36-39)$. Yet, the neonatal rat differs significantly from the human infant. The rat is an altricial species and is relatively immature at birth, with most maturation of the gastrointestinal tract occurring postnatally in close coordination with weaning. In contrast, the human is a precocial species, and many gastrointestinal functions are mature at birth, though the composition of the diet of the newborn does not necessarily require such maturity $(40,41)$. Intestinal maturation in the rat is also closely coordinated with postnatal surges in hormones, particularly corticosteroids and thyroid hormone, which increase in the plasma just before a reduction in intestinal lactase activity and an increase in sucrase activity $(38,40)$. These hormones appear to modulate the expression of these disaccharidases, which is initiated by genetically programmed developmental cues $(38,40)$. The developing swine is in many ways closer to the human infant than the rat with regard to maturation of gastrointestinal function, with early decline in intestinal lactase activity, increase in sucrase activity, and intestinal closure to macromolecule permeability $(30,38)$. Plasma cortisol levels in the piglet are high at birth and decline to adult levels by $5 \mathrm{~d}$ of age (42). In contrast, plasma concentrations of thyroxine and triiodothyronine are maximal at 23 and $16 \mathrm{~d}$ of age, respectively, after much gastrointestinal maturation has already occurred (43). Because our previous in vivo studies have shown that the magnitude of modulation of apolipoprotein expression by lipid absorption is maximal in the 2-d-old newborn piglet $(27,28)$, as well as basal apolipoprotein expression compared to other postnatal developmental groups $(1,27,28)$, we chose this developmental stage for the present explant studies.

EGF is a small (molecular mass $=6054 \mathrm{D}$ ) polypeptide found in several body fluids, including gastrointestinal secretions, breast milk, and amniotic fluid $(39,44)$. It exerts a trophic effect on epithelia, including the intestinal mucosa, with stimulation of maturation and cellular proliferation $(39,44)$. EGF binds to a protein kinase membrane receptor that autophosphorylates and sets a phosphorylation cascade into effect, resulting in stimulation of ornithine decarboxylase and DNA synthesis (39). The role of EGF in the ontogeny of mammalian small intestinal function is not precisely defined. In vivo and in vitro studies to date in pre- and postnatal rodents, as well as human fetal explants, have provided conflicting results with regard to the effects of parenteral and luminal EGF on small intestinal DNA and protein synthesis, as well as brush border disaccharidase activities $(36,37,39,44-48)$. Furthermore, it is not certain at what level EGF may exert some of these effects, because some effects noted in the intact animal are not found in intestinal culture studies, suggesting that the intestinal EGF effects may be part of a systemic response to EGF (45). In the present study, EGF was added to the explant medium at a concentration that approximates the upper limit of the concentration in human colostrum (49). At this concentration, EGF significantly stimulated total protein synthesis in the piglet jejunal explants. In addition, apo A-I and apo A-IV synthesis, expressed as a percentage of total protein synthesis, increased significantly with EGF treatment. The cellular mechanisms of these effects on apolipoprotein synthesis are unknown, but two possibilities exist. The first is induction of a generalized increase in cellular protein synthesis, as reflected by the increase in total protein sp act. However, only synthesis of apo A-I and A-IV was affected, and the increase in apolipoprotein synthesis was proportionately greater than that of total explant protein synthesis, because apolipoprotein synthesis, expressed as a percentage of total protein synthesis, significantly increased. The second possibility is a more specific action of EGF on induction of the apo A-I and AIV genes, possibly though trans-acting transcription regulatory factors, such as has been demonstrated for the increase in transcription of the gastrin gene induced by EGF $(50)$. This mechanism may be further supported by the fact that the apo A-I and A-IV genes are located in a cluster with apo C-III (51). Interestingly, the addition of hydrocortisone to the EGF abolished the EGF-induced increase in total protein, apo A-I, and apo A-IV synthesis. The combination of EGF and hydrocortisone also modestly decreased apo B-48 synthesis. The mechanism of these inhibitory effects of hydrocortisone is unknown at present, but may involve induction of an intermediate that blocks the stimulatory effect of EGF at some level. This inhibitory effect may be teleologically important if the down-regulation of synthesis of these apolipoproteins is advantageous to the organism during times of stress (such as premature weaning) or in the immediate newborn period when piglet serum cortisol levels are extremely high (42).

Hydrocortisone alone lacked effect on either total protein synthesis or apolipoprotein synthesis in piglet jejunal explants, although it was added to the explants at a concentration comparable to that found in the plasma of the newborn piglet (42), as well as the concentration shown to induce lactase, alkaline phosphatase, and DNA synthesis in human fetal small intestinal explants (34). Yet, the combination of hydrocortisone and insulin greatly increased total protein and apo A-IV synthesis and effected a modest increase in apo A-I synthesis. Insulin treatment alone caused a modest increase in apo A-IV synthesis. With regard to the cellular mechanisms of these actions of insulin and hydrocortisone, one may speculate that our observations are due to a global stimulation of cellular protein synthesis, although, as we noted above for the effects of EGF, apo A-I and A-IV synthesis was affected disproportionately to total protein synthesis. In addition, glucocorticoids generally exert a proteolytic effect resulting in overall negative nitrogen balance. Specific induction of the apo A-I and A-IV genes by insulin and hydrocortisone is certainly possible. The human, rat, and mouse apo A-IV genes contain sequences in the $5^{\prime}$ upstream region and exon 1 that are homologous to consensus sequences for glucocorticoid responsive elements (52). The additive action of hydrocortisone with insulin in our studies may be due to the requirement by insulin of an intermediary induced by hydrocortisone for full induction of apolipoprotein gene transcription. Studies are underway to elucidate these issues. In the intact animal, plasma insulin levels vary over a wide range depending upon the glycemic state of the piglet and environmental temperature (53). Also, insulin in breast milk has been shown to affect glucose metabolism in the newborn piglet (54). Therefore, the effect of the interaction of these two hormones may be important in the postprandial period. A similar effect on apo A-IV expression in mature rat hepatocytes by corticosteroid and insulin has been reported by Elshourbagy et al. (23). These investigators noted an increase in apo A-IV mRNA abundance in primary cultures of rat hepatocytes incubated with dexamethasone and insulin, both singly and in combination (23). It is possible that a similar regulatory mechanism is present in the newborn piglet small intestine, although we did not observe a significant effect with hydrocor- 
tisone alone. Perrin-Ansart et al. (25). studied apo A-I synthesis in intestinal explants from fetal and newborn rats. The addition of dexamethasone to the culture medium lacked effect on explant apo A-I synthesis at $\mathrm{d} 18$ of gestation or at postnatal ages 0,2 , and $5 \mathrm{~d}(25)$. Yet, apo A-I synthesis was stimulated by dexamethasone at $\mathrm{d} 20$ of gestation. The addition of insulin to the dexamethasone in those studies did not enhance the effect of dexamethasone alone. The lack of glucocorticoid effect on apo A-I synthesis in the newborn rat pup explants agrees with our findings in explants from the newborn piglet. However, we did observe a stimulation of apo A-I synthesis with the combination of insulin and hydrocortisone. We speculate that our results may vary from those obtained in the rat because of species differences.

In the present study, thyroid hormone lacked effect on synthesis of total protein or any of the apolipoproteins. This finding may not be surprising because the plasma level of thyroxine in the piglet peaks at $3 \mathrm{wk}$ of age (43), and enterocytes may not be responsive in the immediate newborn period. However, any conclusions regarding the lack of effect of thyroid hormone in these studies must be cautiously drawn because we did not have a positive control (a parameter positively modulated by thyroid hormone). In addition, we did not eliminate the possibility of thyroid hormone degradation during the course of the experiments and did not assess explant thyroxine uptake, receptor status, or cellular deiodination pathways.

With regard to our methodology for determining apolipoprotein synthesis in the explants, insulin and hydrocortisone are known to have pronounced and different effects on protein metabolism, and in protein radiolabeling studies the intracellular free amino acid pool and sp act reflect the net effects of protein synthesis and breakdown. Therefore, it is possible that our results may partially reflect a change in precursor methionine sp act. However, explants were cultured in Williams' medium E, which contains methionine at $100 \mu \mathrm{mol} / \mathrm{L}$ concentration, at all times, including the radiolabeling period. Therefore, the extracellular methionine pool probably remained relatively constant, although we did not measure medium methionine levels. The intracellular methionine concentration was not measured either. Although it is unlikely that the explants were intracellularly depleted in the face of provision of extracellular methionine, this possibility cannot be ruled out.

In summary, we have determined optimum conditions for the short-term culture of newborn piglet small intestinal explants to support apolipoprotein synthesis. Apo B-48, A-I, and A-IV were all synthesized by fasting newborn piglet jejunal explants cultured in serum-free medium. Apo B-48 synthesis was not affected by any additives except the combination of EGF and hydrocortisone, which slightly decreased synthesis. Apo A-I synthesis was significantly increased by EGF. This EGF-induced increase in apo A-I synthesis was blunted by concomitant treatment with hydrocortisone. In contrast, the combination of insulin and hydrocortisone induced a significant increase in apo A-I synthesis. Although EGF and insulin increased apo A-IV synthesis, the combination of insulin and hydrocortisone treatment up-regulated apo A-IV synthesis by 2.6-fold. Thyroid hormone treatment lacked effect on the synthesis of any of the apolipoproteins studied. EGF, glucocorticoids, and insulin, along with luminal lipid absorption $(27,28)$, may play regulatory roles in the developmental expression of apolipoprotein synthesis in the neonatal small intestine. Further studies are underway in this laboratory to delineate the molecular mechanisms of this regulation.

Acknowledgment. The authors thank Patricia L. RohwerNutter for her expert technical assistance.

\section{REFERENCES}

1. Black DD, Davidson NO 1989 Intestinal apolipoprotein synthesis and secretion in the suckling pig. J Lipid Res 30:207-218

2. Kane JP 1983 Apolipoprotein B: structural and metabolic heterogeneity. Ann Rev Physiol 45:637-650
3. Olofsson S-O, Bjursell G, Bostrom K, Carlsson P, Elovson J, Protter AA, Reuben MA, Bondjers G 1987 Apolipoprotein B: structure, biosynthesis, and role in the lipoprotein assembly process. Atherosclerosis $68: 1-17$

4. Knott TJ, Pease RJ, Powell LM, Wallis SC, Rall SC, Innerarity TL, Blackhart B, Taylor WH, Marcel Y, Milne R, Johnson D, Fuller M, Lusis AJ, McCarthy BJ, Mahley RW, Levy-Wilson B, Scott J 1986 Complete protein sequence and identification of structural domains of human apolipoprotein B-100. Nature 323:734-738

5. Hu DY, Innerarity TL, Milne RW, Marcel YL, Mahley RW 1984 Binding of chylomicron remnants and beta VLDL to hepatic and extra-hepatic lipoprotein receptors: a process independent of apolipoprotein B-48. J Biol Chem 259:15060-15068

6. Glickman RM, Rogers M, Glickman JN 1986 Apolipoprotein B synthesis by human liver and intestine in vitro. Proc Natl Acad Sci USA 83:5296-5300

7. Chapman MJ 1986 Comparative analysis of mammalian plasma lipoproteins. Methods Enzymol 128:70-143

8. Davidson NO, Glickman RM 1985 Apolipoprotein A-I synthesis in rat small intestine: regulation by dietary triglyceride and biliary lipid. J Lipid Res 26 : 368-379

9. Wu AL, Windmueller HG 1979 Relative contribution by liver and intestine to individual plasma apolipoproteins in the rat. J Biol Chem 254:7316-7322

10. Zannis VI, Kurnit DM, Breslow JL 1982 Hepatic apo A-I and apo E and intestinal apo A-I are synthesized in precursor isoprotein forms by organ cultures of human fetal tissues. J Biol Chem 257:536-544

11. Fielding CJ, Shore VG, Fielding PE 1972 A protein co-factor of lecithin: cholesterol acyltransferase. Biochem Biophys Res Commun 46:1493-1498

12. Green PHR, Glickman RM, Saudek CD, Blum CB, Tall AR 1979 Human intestinal lipoproteins: studies in chyluric subjects. J Clin Invest 64: 233-242

13. Green PHR, Glickman RM, Riley JW, Quinet E 1980 Human apolipoprotein A-IV: intestinal origin and distribution in plasma. J Clin Invest 65:911-919

14. Magun AM, Mish B, Glickman RM 1988 Intracellular apo A-I and apo B distribution in rat intestine is altered by lipid feeding. $\mathrm{J}$ Lipid Res 29 : $1107-1116$

15. Magun AM, Brasitis TA, Glickman RM 1985 Isolation of high density lipoproteins from rat intestinal epithelial cells. J Clin Invest 75:209-218

16. Fidge NH 1980 The redistribution and metabolism of iodinated apolipoprotein A-IV in rats. Biochin Biophys Acta 619:129-141

17. Bisgaier CL, Sachdev OP, Megna L, Glickman RM 1985 Distribution of apolipoprotein A-IV in human plasma. J Lipid Res 26:11 25

18. Steinmetz A, Utermann G 1985 Activation of lecithin:cholesterol acyltransferase by human apolipoprotein A-IV. J Biol Chem 260:2258-2264

19. Chen CH, Albers JJ 1985 Activation of lecithin:cholesterol acyltransferase by apolipoproteins E-2, E-3, and A-IV isolated from human plasma. Biochim Biophys Acta 836:279-285

20. Stein O, Stein Y, Lefevre M, Roheim PS 1986 The role of apolipoprotein AIV in reverse cholesterol transport studied with cultured cells and liposomes derived from an ether analog of phosphotidylcholine. Biochim Biophys Acta 878:7-13

21. Dvorin E, Gorder NL, Benson DM, Gotto AM 1986 Apolipoprotein A-IV: a determinate for binding and uptake of high density lipoproteins by rat hepatocytes. J Biol Chem 261:15714-15718

22. Rubin DC, Ong DE, Gordon JI 1989 Cellular differentiation in the emerging fetal rat small intestinal epithelium: mosaic patterns of gene expression. Proc Natl Acad Sci USA 86:1278-1282

23. Elshourbagy NA, Boguski MS, Liao WSL, Jefferson LS, Gordon JI, Taylor JM 1985 Expression of rat apolipoprotein A-IV and A-I genes: mRNA induction during development and in response to glucocorticoids and insulin. Proc Natl Acad Sci USA 82:8242-8246

24. Fernando-Warnakulasuriya GJP, Eckerson ML, Clark WA, Wells MA 1983 Lipoprotein metabolism in the suckling rat: characterization of plasma and lymphatic lipoproteins. J Lipid Res 24:1626-1638

25. Perrin-Ansart MC, Vacher D, Girard-Globa A 1988 Determination of apolipoprotein A-I synthesis in intestinal explants from fetal and neonatal rats. Biochim Biophys Acta 963:541-548

26. Demmer LA, Levin MS, Elovson J, Reuben MA, Lusis AJ, Gordon JI 1986 Tissue-specific expression and developmental regulation of the rat apolipoprotein B gene. Proc Natl Acad Sci USA 83:8102-8106

27. Black DD, Rohwer-Nutter PL, Davidson NO 1990 Intestinal apo A-IV gene expression in the piglet. J Lipid Res 31:497-505

28. Black DD, Rohwer-Nutter PL 1991 Intestinal apolipoprotein synthesis in the newborn piglet. Pediatr Res 29:32-38

29. Black DD 1992 Effect of intestinal chylomicron secretory blockade on apolipoprotein synthesis in the newborn piglet. Biochem J 283:81-85

30. Corring T, Durand G, Henry Y 1982 Some aspects of development and nutrition in the monogastric animal during postnatal life. World Rev Nutr Diet 39:124-190

31. Kedinger M, Haffen K, Simon-Assmann P 1987 Intestinal tissue and cell cultures. Differentiation 36:71-85

32. Davidson NO, Kollmer ME, Glickman RM 1986 Apolipoprotein B synthesis in rat small intestine: regulation by dietary triglyceride and biliary lipid. $\mathrm{J}$ Lipid Res 27:30-39

33. Markwell MK, Haas SM, Bieber LL, Tolbert NE 1978 A modification of the Lowry procedure to simplify protein determination in membrane and lipoprotein samples. Anal Biochem 87:206-210

34. Arsenault $P$, Menard D 1985 Influence of hydrocortisone on human fetal small intestine in organ culture. J Pediatr Gastroenterol Nutr 4:893-901 
35. Menard D, Arsenault P 1985 Explant culture of human fetal small intestine. Gastroenterology 88:691-700

36. Conteas CN, DeMorrow JM, Majumdar APN 1986 Effect of epidermal growth factor on growth and maturation of fetal and neonatal rat small intestine in organ culture. Experientia 42:950-952

37. Berseth CL 1987 Enhancement of intestinal growth in neonatal rats by epidermal growth factor in milk. Am J Physiol 253:G662-G665

38. Henning SJ 1987 Functional development of the gastrointestinal tract. In: Johnson LR (ed) Physiology of the Gastrointestinal Tract, 2nd Ed. Raven Press, New York, pp 285-300

39. Lebenthal E, Leung Y-K 1987 Epidermal growth factor (EGF) and the ontogeny of the gut. J Pediatr Gastroenterol Nutr 6:1-5

40. Auricchio S, Sebastio G 1989 Development of disaccharidases. In: Lebenthal E (ed) Human Gastrointestinal Development. Raven Press, New York, pp $451-470$

41. Grand RJ, Watkins JB, Torti FM 1976 Development of the human gastrointestinal tract. A review. Gastroenterology 70:790-810

42. McCauley I, Hartmann PE 1984 Changes in piglet leucocytes, B lymphocytes, and plasma cortisol from birth to three weeks after weaning. Res Vet Sci 37: 234-241

43. Scanes CG, Lazarus D, Bowen S, Buonomo FC, Gilbreath RL 1987 Postnatal changes in circulating concentrations of growth hormone, somatomedin $\mathrm{C}$, and thyroid hormones in pigs. Domest Anim Endocrinol 4:253-257

44. Weaver LT, Walker WA 1988 Epidermal growth factor and the developing human gut. Gastroenterology 94:845-847

45. Menard D, Arsenault P, Gallo-Payet N 1986 Epidermal growth factor does not act as a primary cue for inducing developmental changes in suckling mouse jejunum. J Pediatr Gastroenterol Nutr 5:949-955

46. Menard D, Arsenault P, Pothier P 1988 Biologic effects of epidermal growth factor in human fetal jejunum. Gastroenterology 94:656-663

47. Pollack PF, Goda T, Colony PC, Edmond J, Thornburg W, Korc M, Koldovsky O 1987 Effects of enterally fed epidermal growth factor on the small and large intestine of the suckling rat. Regul Pept 17:121-132

48. Malo C, Menard D 1982 Influence of epidermal growth factor on the development of suckling mouse intestinal mucosa. Gastroenterology 83:28-35

49. Beardmore JM, Lewis-Jones DI, Richards RC 1983 Urogastrone and lactose concentrations in precolostrum, colostrum, and milk. Pediatr Res 17: $825-828$

50. Godley JM, Brand SJ 1989 Regulation of the gastrin promoter by epidermal growth factor and neuropeptides. Proc Natl Acad Sci USA 86:3036-3040

51. Karathanasis SK 1985 Apolipoprotein multigene family: tandem organization of human apolipoprotein A-I, C-III, and A-IV genes. Proc Natl Acad Sci USA 82:6374-6378

52. Staels B, van Tol A, Verhoeven G, Auwerx J 1990 Apolipoprotein A-IV messenger ribonucleic acid abundance is regulated in a tissue-specific manner. Endocrinology 126:2153-2163

53. Close WH, Dividlich JL, Duee PH 1985 Influence of environmental temperature on glucose tolerance and insulin response in the new-born piglet. Biol Neonate 47:84-91

54. Nowak J 1989 The influence of insulin loading tests per os on insulin and glucose concentrations in blood of piglets within 40 hours from birth. Arch Exp Veterinaermed 43:67-72 